\title{
EL GOCE TOTALITARIO — SALÒ DE PASOLINI
}

\section{Eduardo Subirats ${ }^{1}$}

Resumo: Há duas características fundamentais que definem o sentido espiritual e civilizatório da tortura. Uma delas é de ordem política. Em termos extremamente rudimentares, isso pode ser formulado mediante a exemplaridade criminal com que certos setores que estão na vanguarda da organização política e militar do estado de direito anunciam seu próprio poder de sedição como a base para uma nova ordem de fato local ou global. É por causa dessa razão que a tortura - seja ela do tipo como a praticada durante a Inquisição colonial do séc. XVI, seja ela da sorte como a praticada nas penitenciárias coloniais da Guerra Global atual — precisa ocultar a sua brutalidade primitiva, sangrenta e sacrificial da sociedade, enquanto que, ao mesmo tempo, precisa assegurar a exibição de si mesma como uma demonstração pública de poder que é tão absoluta quanto arbitrária. Saló fornece uma denúncia da tortura, mas simultaneamente interpreta a tortura como a escrita secreta de uma modernidade que legitima e dissemina tortura enquanto linguagem. $E$, por último, este filme também anuncia o advento de um novo fascismo global: o fascismo global que encara nossa face hoje.

Palavras-Chave: Teologia da tortura; Fascismo global; Crítica fílmica e social.

\begin{abstract}
There are two fundamental characteristics that define the spiritual and civilizing significance of torture. One is political. In extremely crude terms, it can be formulated as the criminal exemplarity with which certain sectors that are at the vanguard of political and military organization of a legal state publicly proclaim their own seditious power as the source of a new de facto local or global order. It is for this reason that torture - whether of the sort practiced during the colonial Inquisition of the Sixteenth century or of the kind practiced in the colonial penitentiaries of the current Global War - must hide its primitive, bloody, and sacrificial brutality from society while, at the same time, making sure to exhibit itself as a public demonstration of a power that is as absolute as it is arbitrary. Salo provides a denunciation of torture; but at the same time it interprets torture as the secret writing of a modernity that legitimizes and disseminates torture as a language. Last but not least, this film also announces the coming of a new global fascism: the global fascism that is staring us in the face today.

Key Words: Theology of Torture; Global Fascism; Film and Social Critique.
\end{abstract}

1 Professor da New York University; estudou filosofia em Barcelona, Paris e Berlim; já foi docente de filosofia, estética, arquitetura, literatura e teoria da cultura nas universidades de São Paulo, Caracas, Madrid, México e Princeton; dentre outras, é autor das obras: $D a$ vanguarda ao pós-moderno (3. ed. 1987) e A existência sitiada (2010). Endereço eletrônico: eduardo.subirats@nyu.edu. 


\section{LA BASTILLE}

En su Directorium Inquisitorum, el tratado sobre interrogatorios y torturas inquisitoriales de 1503, Nicolau Eimeric formuló una regla de oro. Según este teólogo, la tortura no debe considerarse bajo ningún pretexto como un simple juego arbitrario del crimen institucionalmente amparado en el nombre de Dios. Por el contrario, sus técnicas e instrumentos están sujetos específica y razonadamente a un último valor trascendente, y es precisamente este significado espiritual de la tortura el que otorgaba al verdugo la más alta dignidad teológica. Eimeric se oponía drásticamente a la práctica común de quebrar huesos en los interrogatorios a "personas desamparadas", puesto que carecía de toda función racional. En cambio, proponía tecnologías conceptualmente astringentes para individuos socialmente relevantes, como médicos, soldados y sacerdotes que practicasen la herejía. En esos casos, las torturas debían diseñarse bajo principios teológicamente diferenciados para cada clase de trasgresión dogmática y para cada caso personal. La tortura debía y debe considerarse como el más eficaz y significativo instrumento de formación o configuración del espíritu humano ${ }^{2}$.

Reducir la tortura a la categoría de problema tecnológico, confinarla sociológicamente a administraciones corruptas y sistemas políticos tiránicos, o enclaustrarla en nombre de la ley bajo un principio más o menos virtuoso y virtual de derechos humanos no significa mucho más, de acuerdo con esta filosofía inquisitorial, que desconocer sus últimos fundamentos teológicos. La tortura no es una expresión entre muchas otras de la adversidad o la perversión humana. Más bien constituye la forma más pura y gozosa de la dominación del humano por el propio humano y, en este misma medida, debe relacionarse con otras manifestaciones del poder político. Más aún: desde el punto de vista teológico y político que arroja la larga tradición de crímenes, torturas y ultrajes de la Inquisición en nombre de los valores del cristiandad que fundan el orden de la civilización occidental es preciso analizar la tortura como instrumento inherente al estado moderno y la civilización contemporánea, junto a otros fenómenos asimismo ejemplares como son la destrucción tecnocientífica de los ecosistemas, las estra-

2 EYMERICH, Nicolau; PEÑA, Francisco. Le manuel des inquisiteurs. Paris: Mouton Éditeur, 1973, p. 207 et seq. [Directorium Inquisitorum. Barcelona, 1503].

194 Número temático: literatura e cinema. A Cor das Letras - UEFS, n. 11, 2010 
tegias económicas de genocidios globales, o los programas de exterminio nuclear y biológico del género humano. Eso quiere decir que la tortura no sea una más entre esas formas e instrumentos de dominación, o que sólo constituye uno de sus instrumentos extremos o perversos; más bien constituye su expresión antropológica o espiritualmente privilegiada.

Sería asimismo incierto trivializar la tortura como daño colateral o secuela indeseable de los aparatos políticos o militares de dominación. Los métodos e instrumentos de tortura ponen más bien de manifiesto las subestructuras morales, epistemológicas y políticas de los sistemas que la ejecutan. Por esta razón precisamente, por revelar las estructuras fisiológicas y psicológicas más íntimas de la teología, la psicología y la teoría política de los sistemas de dominación y control humanos es por lo que sus prácticas se ocultan siempre a la luz pública. Tal vez deban recordarse aquí dos interpretaciones clásicas a este propósito. "Die Waffen sind nichts anderes, als das Wesen der Kämpfer selber" - escribió G. W. F. Hegel en su Phänomenologie des Geistes. Las armas son la esencia de sus portadores. Reflejan la naturaleza de la conciencia racional de la civilización que las emplea. Pero este axioma se aplica necesariamente con mayor rigor allí dónde estos instrumentos de terror, destrucción y avasallamiento afectan de manera directa a la existencia individual en su totalidad ${ }^{3}$. Por otra parte, Franz Kafka describe en su relato In der Straflkolonie al cuerpo torturado como la superficie de registro en la que se labra y puntea el sistema legal que rige en el campo de concentración y exterminio como metáfora de la civilización moderna. En otras palabras: la tortura es al mismo tiempo el medio privilegiado de inscripción y representación ejemplar de la racionalidad y el rigor de la ley.

La tortura es un microcosmos. De ahí su alto valor teológico, filosófico y político. Las técnicas físicas y químicas de destrucción de la existencia humana - desde los garfios y mutilaciones que practicaba la Inquisición hasta las descargas eléctricas, las drogas, las contusiones violentas, la asfixia prolongada, los estímulos sensoriales agresivos o la violación sexual adiestrados en los centros de inteligencia militar de la Guerra fría y la Guerra global - no distinguen a un inexpresable e incomprensible sistema de terror, como pretenden y proclaman los watchdogs institucionales y mediáticos de los human rights. Por el contrario, constituyen la expresión racional y calculada que define a la modernidad. Es este el mismo nexo entre tortura

3 HEGEL, Georg Wilhelm Friedrich. Die Phänomenologie des Gesties, A [1807], p. 320. Cláudio Cledson Novaes, Fernanda Aguiar C. Martins, Roberto H. Seidel (Org.) 
y racionalidad civilizadora que expuso el Marquis de Sade en sus memorias de cárcel: Les 120 journées de Sodome.

La configuración literaria de la tortura sadiana es esclarecedora en nuestro panorama contemporáneo de guerras, genocidios y escarnio de la masa electrónica global por varios motivos. Los propósitos criminales de sus imaginarias sociedades secretas les obligaban a una situación de exclusión social y desafuero jurídico, metafóricamente representada en la imagen mística del castillo oculto en un lugar inaccesible e inexpugnable. Pero Sade no formulaba este confinamiento de sus libertinos como la condición negativa de asociaciones criminales fuera de la ley. Por el contrario, definía metafóricamente aquel estado de excepción a partir del cual se constituyeron el orden jurídico y moral de un sistema racional y revolucionario de dominación. Los libertinos de Sade fueron los instrumentos que ejecutaron la última consecuencia moral y política de la razón filosófica e histórica de la Grande Revolution, la misma razón que instituyó la guillotine y la dictadura revolucionaria. La misma razón que erigió los altares sacrificiales a la libertad y abrió las puertas a las guerras napoleónicas. La misma que inauguró una nueva era de expolio, explotación y genocidios coloniales. Su violencia configura el nuevo orden racional republicano al igual que lo formula la teoría del estado de excepción, como condición constituyente del estado totalitario en Thomas Hobbes o en Carl Schmitt ${ }^{4}$. Así como lo hemos presenciado en el proceso de expansión y dominación militares que han culminado con la tortura y el exterminio públicos de prisioneros de guerra en los campos de tortura y ejecución de Guantánamo o Abu Ghraib. La ejemplaridad moral y la función jurídica y filosófica de los libertinos sadianos explican la escrupulosidad con la que Sade describe el rigor lógico, el orden geométrico, las estrictas normas y jerarquías formales, y la vigilada transparencia de sus performances criminales. $Y$ explica asimismo, su puntillosa ponderación de un sistema de control administrativo total que comprende tanto la actuación moral como el goce de las víctimas o los verdugos indistintamente $\mathrm{e}^{5}$. Por eso también la sociedad secreta sadiana es una anticipación visionaria de la organización totalitaria inherente a las burocracias militares y

4 SCHMITT, Carl. Der Begriff des Politischen. Berlin: Dunker\&Humblot, 1963, p. 34 et seq.; AGAMBEN, Giorgio. Homo sacer: sovereign power and bare life. Stanford: Stanford University Press, 1998, p. 30 et seq.

5 The Marquis de Sade. The 120 days of Sodom, and other writings. Compiled and translated by Austryn Wainhouse and Richard Seaver. New York: Grove Press, 1966, p. 240 et seq. 
políticas globales modernas, como ya señalaron Max Horkheimer y Theodor W. Adorno en su Dialektik der Aufklärung ${ }^{6}$.

Pero la filosofía de Sade va mucho más allá que la simple explicación de la función jurídica constituyente de la violencia anterior o exterior a la ley. Sade no fue un ideologue. Tampoco un teórico del estado totalitario moderno. Su obra literaria pone de manifiesto, más bien, las premisas lógicas y epistemológicas, y las consecuencias político-económicas y morales del nuevo orden político y metafísico de la Revolution, a través de un performance repetitivo y tedioso, de un goce monacalmente sistematizado, de una combinatoria de órganos more geométrico, y de la racionalización industrial de la violación, la tortura y el crimen. Sade despliega la subestructura lógica del sistema de la civilización moderna: liberal y totalitaria, esclarecida y destructiva, progresista y apocalíptica.

Dos características distinguen este significado civilizador de la tortura. Una es política y se formula en términos muy crudos como la ejemplaridad criminal con que determinados sectores vanguardistas de la organización política y militar del estado de derecho exhiben su poder sedicente como fuerza constitutiva de un nuevo orden local o global. Ello explica una paradoja común a las organizaciones eclesiásticas o militares que, bajo una u otra forma, han practicado el terror y la tortura como fue el caso de la Inquisición colonial o de las fuerzas paramilitares de la era postcolonial. Estas organizaciones tienen que ocultar a la sociedad su práctica normal de violencia porque les privaría de toda legitimidad. Al mismo tiempo tienen que exhibirla como representación pública de su poder y su terror. El caso de Giordano Bruno, sometido durante seis años a interrogatorios y tortura en las prisiones secretas del Vaticano, para ser quemado vivo en el mercado público tras arrancarle la lengua, ilustra esta doble dimensión oculta $y$, al mismo tiempo, exhibicionista de la tortura.

La obra de Sade pone de manifiesto que la racionalidad que sostenían los ideales ilustrados de la libertad y la igualdad del sistema republicano, llevaba, en su última consecuencia, a perpetrar los mismos actos de terror que habían distinguido el Antiguo régimen. La opresión, la destrucción, la rapiña y el escarnio: jesos eran sus postulados! Por eso Les 120 journées de Sodome anticipan la llamada "dialéctica del esclarecimiento", la doble cara de una razón revolucionaria que, al mismo tiempo, entraña una maquinaria política y militar totalitaria.

6 HORKHEIMER, Max; ADORNO, Theodor Wiesegrund. Dialektik der Aufklärung. Frankfurt: S. Fischer Verlag, 1969, p. 88 et seq.

Cláudio Cledson Novaes, Fernanda Aguiar C. Martins, Roberto H. Seidel (Org.) 


\section{De Saló a Abu Ghraib}

Salò, o le 120 giornate di Sodoma de Pier Paolo Pasolini es, en primer lugar, el testimonio intelectual de una edad de guerras imperialistas, ultraje mediático y genocidio ${ }^{7}$. El film narra específicamente las prácticas de violación sexual, tortura y ejecución practicadas al amparo de los estados fascistas europeos en torno a las guerras de los años cuarenta del siglo pasado. Pero Pasolini hace algo más que documentar un caso real de crimen organizado: lo pone a contraluz de una crítica de la civilización tardomoderna. Más allá de esta alegoría política sobre el crimen estatal y eclesiásticamente organizado, Salò es una denuncia del nihilismo moral que ha impregnado la filosofía moderna de Sade, Nietzsche o Klossowsky, precisamente a través de sus iluminaciones filosóficas más cáusticas. Y cuyas citas Pasolini pone en boca de los verdugos fascistas y bajo el decorado que brindan los íconos de la vanguardia futurista, de Fernand Léger y Lyonell Feininger a Carlo Carrá. Salò es una denuncia de la tortura, pero al mismo tiempo es su interpretación como la escritura secreta de aquella modernidad que la legitima y difunde. En este sentido fue un anuncio del nuevo fascismo global que hoy tenemos frente a nuestros ojos.

Por lo demás, la película expone tres definiciones, o tres aspectos de la práctica institucional de la tortura. Esta puede definirse, en primer lugar, como el goce (Lust) sexual ligado a la destrucción, a la humillación y a la muerte sacrificial. Más aún, Pasoloni muestra la santa trinidad de excitación libidinal, violación sexual y asesinato, junto a las fantasías narcisistas de omnipotencia que los acompaña, como los signos de aquel mismo colapso de la humanidad que Freud había anunciado décadas antes en su diagnóstico de la modernidad como una cultura de la violencia. Saló pone de manifiesto este mismo colapso a través de las imágenes de hombres y mujeres violados y mutilados en la danza macabra del poder absoluto que cierra sus últimas secuencias.

Segundo: en Salò la tortura se eleva a la expresión suprema de la libertad. Pues ningún ideal moral de soberanía, por paranoico o absolutista que sea su voluntad de poder, puede manifestar de una manera más transparente la emancipación de cualquier freno jurídico, su independencia de cualquier norma moral y su hegemonía más allá de cualquier límite técnico.

7 PASOLINI, Pier Paolo. Salò, The 120 Days of Sodom. 1975.

198 Número temático: literatura e cinema. A Cor das Letras - UEFS, n. 11, 2010 
Y ningún principio de dominación puede cumplirse de una manera a la vez tan inocente, absoluta e impecable como en la relación del verdugo con su víctima. Sólo en la tortura la libertad trascendental de la razón tecnocientífica y moral se cumple al mismo tiempo como fantasía de omnipotencia y como goce de la verdadera an-arquía (el estado anterior a la constitución de un archon o gobierno), según pronuncia expresamente uno de los libertinos de Pasolini.

El tercer significado de la tortura es estético. Pero quizás deba hablarse precisamente de una múltiple función estética de la tortura, y quizás pueda recordarse la profusa imaginería de violaciones y mutilaciones, bombardeos masivos y asesinatos que distinguen la pequeña pantalla del global village en estos últimos años de transición al nuevo siglo. Esta dimensión estética o, más exactamente, performática de la tortura merece especial atención.

En Les 120 journées la tortura y el asesinato se presentaban bajo el formato de un escenario barroco. Eran crímenes perpetrados para ser vistos, y en su goce participaban a partes iguales el libertino como actor, y el lector como voyeur. Pasolini retoma esta dimensión escénica. Y lo hace bajo una variedad de aspectos. La estetización del horror es uno de ellos. El genocidio ejemplar de Salò tiene lugar en una elegante villa paladiana cuyo interior exhibe las obras maestras de las vanguardias artísticas bajo un ambiente de refinamiento literario. También en este sentido Pasolini anticipa la estetización del horror a través de las mise en scène mediáticas: las víctimas de Guantánamo clínicamente uniformadas de color naranja, transportadas en camillas a sus salas de tortura en un sobrio espectáculo de violencia hipermoderna.

Pero la película Saló también plantea esta estetización de la tortura bajo la forma de un teatro incorporado dentro del cine. A este respecto es importante subrayar la utilización por Pasolini de las alcahuetas sadianas como narradoras que introducen subrepticiamente aquella misma distancia y extrañamiento (Befremdung) con respecto a la representación que Brecht había formulado como medio de esclarecimiento artístico. Esta duplicación de la representación de la tortura es reflexiva y, como tal, se enfrenta polémicamente con dos características elementales de la representación de la violencia en la aldea global: la ficcionalización, trivialización y gasificación mediáticas de su realidad, y la exaltación hiperrealista de la violencia. A diferencia de esta trivialización del crimen por la industria cinematográfica el distanciamiento reflexivo frente al escenario de la tortura es lo que trans- 
forma a Salò en un crudo manifiesto y una crítica. Por eso el Pasolini fue y sigue siendo un film prohibido, y no lo son, en cambio, la pornografía y la violencia corrientes de las cadenas globales de televisión.

El cuarto significado de la tortura en esta película es político: la constitución de una organización y un poder totales sobre las víctimas. La tortura se revela en ella como una escritura cifrada en el cuerpo de las víctimas y en el goce de los verdugos, lo mismo que en la Strafkolonie de Kafka, e instaurada como sistema de normas opresivas de una sociedad totalitaria ideal. Pasolini muestra la tortura como la dimensión interior de la máquina neutral y autónoma de terror bajo la que la filosofía política ha definido el estado absolutista y totalitario moderno de Hobbes a Schmitt ${ }^{8}$.

\section{EL PROCESO CIVILIZADOR}

Salò no solamente tiene el interés de una denuncia histórica de los crímenes del fascismo pasado. Es también una anticipación del fascismo que ayer era de mañana, como Barth David Schwartz ha subrayado en su biografía de Pasolini ${ }^{9}$. La tortura como expresión de la libertad, la tortura como poder total, la tortura como espectáculo: estas son las dimensiones contemporáneas de la crítica de la razón civilizatoria de Sade y Pasolini.

La película describe este significado a través de la estructura iniciática que recorre: la división en una serie de "círculos" sucesivos por los que las víctimas deben transitar hasta su final consumación sacrificial. Estos círculos son una alusión al Inferno de Dante y su sentido es alegórico. El primero de ellos, el "Girone delle manie" pone en escena un sistema artificial de estímulos y excitaciones. Un sistema que no se priva de los incentivos más extremos, desde la masturbación hasta la ejecución sumaria. Pero se trata de un sistema de incitación y excitación que, en última instancia, genera grados progresivos de frustración, y una subsecuente agresividad destructiva y autodestructiva, tanto en los verdugos, como en las víctimas. Con esta metáfora cierra Pasolini parodia un sistema de incitación al consumo que, ya se trate de los tráficos sexuales, de la producción corporativa de semillas biocidas, o de las economías armamentistas, genera progresivos gradientes

8 SCHMITT, Carl. Der Leviathan in der Staatslehre des Thomas Hobbes. Stuttgart: KlettCotta, 1982, p. 51 et seq.

9 SCHWARTZ, Barth David. Pasolini Requiem. New York: Vintage Books, 1995, p. 637 et seq.

200 Número temático: literatura e cinema. A Cor das Letras - UEFS, n. 11, 2010 
de violencia, el incremento exponencial de hambre, epidemias y muerte, así como la expansión indefinida de la guerra.

En el siguiente "Girone della merda" Pasolini expone la consecuencia necesaria de este primer ciclo capitalista de hiperexcitación libidinal, descargas emocionales frustrantes y la subsiguiente acumulación de energía letal. Asistimos inermes en este círculo a la degradación del humano militarmente obligado a marcar cuchillas, a arrastrarse en cuclillas y engullir los propios excrementos. También una parodia del poder global en el mundo moderno.

La sangre cierra estos ciclos de iniciación a la civilización totalitaria. Bajo su símbolo a la vez vital y sacrificial Salò representa la tortura y mutilación de los órganos de la unión erótica y la generación biológica. Se trata de una tortura política y sexual al mismo tiempo, exactamente como las practicadas por los regímenes fascistas de la Guerra llamada fría en Colombia, Chile o Argentina, y como las que se siguen llevando a cabo bajo los auspicios de la subsiguiente Guerra contra el terrorismo. Semejante simbolismo de la sangre pone también de manifiesto a la tortura como paradigma de la destrucción terminal del humano. Pero Pasolini añade un detalle no menos relevante en la cultura mediática e industrial del siglo 21: la gasificación mediática del dolor y de la agonía humanas en los espectáculos de violencia, destrucción y la muerte. Es su conclusión al goce totalitario.

La última secuencia de Salò es esclarecedora en este sentido precisamente. En una prisión a cielo abierto se somete a las víctimas a torturas y mutilaciones letales. Pero dos de los facciosos contemplan la escena desde un balcón cerrado y a través de unos binóculos. La cámara reproduce el visor por el que se ven los rostros de desesperación y desfallecimiento de las víctimas en un limpio close-up, pero no pueden escucharse sus gritos. En su lugar se oye la exaltación sacra de la sensualidad, el erotismo y la belleza de Carmina Burana como música de fondo. De repente, el libertino invierte la posición de los prismáticos y las imágenes de los cuerpos despedazados se diluyen en la indiferencia de la lejanía, mientras uno de los soldados le masturba. El film muestra a este verdugo voyeur y masturbante de espaldas. Es, por consiguiente, una conciencia anónima. Su función compositiva es identificatoria. Representa al espectador mediático. Somos nosotros.

Tres características distinguen la constitución espiritual de este "nosotros" electrónico en el espectáculo de la Guerra global. El primero de ellos es la ficcionalización de la realidad. Esta gasificación mediática de lo real ha alcanzado en Abu Ghraib al extremo de barajar las fotografías de las 
víctimas reales de torturas letales con imágenes de la industria pornográfica. Pero esta hibridación de ficción y realidad no significa solamente la volatilización de esta última en el sentido de "la guerre qu'na eu lieu". Más importante es la dimensión profunda de este intercambio semiótico entre simulacros y representaciones: la continuidad lingüistica, moral y libidinal del consumo masivo de pornografía electrónica y el goce totalitario de la tortura y asesinato masivo de humanos en prime time.

Un segundo momento distingue Abu Ghraib como símbolo civilizador en la era del espectáculo: sus espacios fragmentarios, la deformación y despersonalización de sus víctimas, y los signos de un terror militar que exhibe una eficiencia tecnocrática hipermoderna y, al mismo tiempo, la estructura esquizofrénica de un poder de formas proteicas, sujetos esquizoides y actuaciones racionalmente incontrolables. Lo que Michel Foucault anunció en su saludo de bienvenida al Anti-Oedipe como una edad deleuziana por venir.

El tercer y último aspecto que cristaliza en este voyeur de Salò que somos nosotros es una consecuencia de los dos anteriores, la evaporación electrónica y la deconstrucción esquizofrénica de la realidad. Se trata de nuestro estado colectivo de rigidez catatónica, de congelamiento intelectual y emocional, y de invalidez tanto práxica como comunicativa. Es el sentido de la última imagen de la película: una pareja de soldados bailan un tango, indiferentes a la realidad que les rodea e intercambian frases banales. Epítome de un estado generalizado de sonambulismo en el que resulta imposible para el humano comprender la realidad del espectáculo y construir un sentido para su existencia.

\section{UNA HUMANIDAD QUE SE DEVORA A SÍ MISMA}

- ¿Por qué estoy viendo esta película? - se preguntaba una estudiante en un seminario sobre Pasolini. Una pregunta que nos hacemos todos ante el horror que sus imágenes despiertan. $Y$ una pregunta que entraña el rechazo espontáneo de este film. Ese horror es el sentimiento que acompaña nuestra experiencia de una realidad que rebasa los límites de nuestro orden moral y nuestra conciencia individual, y los destruye, dejándonos en el vacío, en la incertidumbre, y en medio de un mundo de tinieblas y del no-ser. Nos preguntamos qué sentido tiene ver esta ficción cuando sus imágenes y discursos no parecen tener otro objeto que revelar el 
absurdo de la historia, la fragilidad de la existencia y la impotencia de nuestra conciencia.

- ¿Por qué vemos estos films? - es una pregunta que nos hacemos frente al límite de lo que somos capaces de ver y aprehender sin poner en peligro la integridad moral y la coherencia intelectual de nuestra conciencia. ¿Por qué vemos estas imágenes que nos perseguirán como testimonios de nuestra propia irrealidad en el mundo? ¿Por qué contemplamos paralizados las horrendas imágenes de Pasolini, y de los video-clips de torturas, asesinatos, genocidios y escarnio con los que cada día nos confrontan los medios de comunicación?

La condena moral que se ha impuesto reiteradas veces contra Saló de Pasolini es la hipocresía de nuestro tiempo: el rechazo de una supuesta inmoralidad de las imágenes del film que objetivamente sólo realzan a través de la reflexión artística una realidad que la información pública desactiva a través de sus retóricas, y a través de la fragmentación, aceleración y banalización de sus noticias. Este rechazo moralista es falso y no sólo porque las imágenes de Saló sean históricamente verdaderas. Pasolini expone en primer lugar una interpretación filosóficamente rigurosa de aquella crisis de la razón ilustrada y científica cuyas primeras consecuencias vislumbró Sade, que Nietzsche puso rigurosamente de manifiesto, y cuyos motivos se han reiterado a lo largo del pensamiento intelectual y artístico del siglo veinte. Saló es asimismo una reflexión sobre las atrocidades de la Segunda Guerra Mundial y su absurdo, puesto que desde nuestra perspectiva histórica nada se ha erigido sobre sus cenizas. Y Saló es también una visión desesperada de una humanidad que consuma consumiendo y se devora a sí misma.

Pero, probablemente, lo más terrible en este film no son sus imágenes. Lo más espantoso es que su construcción artística en el medio del film nos hace ser conscientes de una complicidad contemplativa de voyeur con respecto a los mismos escenarios de tortura, genocidio y degradación en las nuevas guerras del siglo 21 de la que estos mismos medios nos hacen inconscientes e inmunes hasta un extremo que raya la imbecilidad. El horror ante estas imágenes no sólo emana de la simpatía y compasión hacia el dolor humano que representan. Es también el sentimiento de los límites y la impotencia de nuestra conciencia que nos acompaña frente a su realidad. Y la trasgresión de estos límites es precisamente la última consecuencia transformadora de toda verdadera obra de arte. 


\section{REFERÊNCIAS}

AGAMBEN, Giorgio. Homo Sacer: Sovereign Power and Bare Life. Stanford: Stanford University Press, 1998.

EYMERICH, Nicolau; PEÑA, Francisco. Le manuel des inquisiteurs. Paris: Mouton Éditeur, 1973. [Directorium Inquisitorum. Barcelona, 1503].

HEGEL, Georg Wilhelm Friedrich. Die Phänomenologie des Gesties, A [1807].

HORKHEIMER, Max; ADORNO, Theodor Wiesegrund. Dialektik der Aufklärung. Frankfurt: S. Fischer Verlag, 1969.

PASOLINI, Pier Paolo. Salò, The 120 Days of Sodom. 1975.

SCHMITT, Carl. Der Begriff des Politischen. Berlin: Dunker\&Humblot, 1963.

SCHMITT, Carl. Der Leviathan in der Staatslehre des Thomas Hobbes. Stuttgart: Klett-Cotta, 1982.

SCHWARTZ, Barth David. Pasolini Requiem. New York: Vintage Books, 1995.

THE MARQUIS DE SADE. The 120 days of Sodom, and other Writings. Compiled and translated by Austryn Wainhouse and Richard Seaver. New York: Grove Press, 1966. 